\title{
Investigation of Influencing Factors on Air Leakage of Canadian Dwellings
}

\author{
Maysoun Ismaiel ${ }^{1 *}$ and Yuxiang Chen $^{2}$ \\ ${ }^{1}$ Phd student, Department of Civil \& Environmental Engineering, University of Alberta \\ ${ }^{2}$ Assistant Professor, Department of Civil \& Environmental Engineering, University of Alberta \\ *Corresponding author's e-mail: ismaiel@ualberta.ca
}

\begin{abstract}
Air leakage is one of the main influencing factors in buildings' thermal performance. The adverse effects of poor air leakage include higher energy costs, consumption in space heating and cooling, poor thermal comfort, corrosion, and the growth of molds due to air leakage induced condensation. The main objective of this study is to investigate the characteristics of air leakages of Canadian homes related to construction methods, age, size and climatic zones. The air leakage test results of 226,000 dwellings in three provinces of Canada were analyzed. Statistical analysis was utilized to compare the mean of air leakage with respect to different factors. Generally, the air leakage decreased by 40\% in the period from 1960 until 2018, which has shown a remarkable effect of new construction techniques on air leakage. Investigations also indicated that the average air leakage rate of homes constructed by using the onsite technique is approximately $25 \%$ to $60 \%$ higher than those prefabricated in modular or panels, varying with respect to the workmanship and construction quality control. This study concluded that the prefabricated construction techniques could decrease the air leakage rate significantly, which will have a remarkable effect on buildings' thermal performance as well as home's heating and cooling costs. The findings contribute to estimating the effects of influencing factors on air leakage, also it is useful in performance simulations, HAVC sizing and energy management. And recommend the use of the prefabricated in modular or panel's construction method to achieve better and acceptable air leakage performance.
\end{abstract}

\section{KEYWORDS}

Air-tightness; Air Leakage; Construction method; Dwelling type; Canada housing; Air Leakage influencing factors

\section{INTRODUCTION}

Reducing air leakage in dwellings is important for improving energy efficiency and thermal comfort. Air infiltration can account for $30 \%$ or more of a home's heating and cooling costs and contribute to problems with moisture, noise, dust and entry of pollutants and insects. Nearly $45 \%$ of this uncontrolled air infiltrates through openings in ceilings, walls and floors as well as through plumbing penetrations as stated by (Gillott et al. 2016)

(Hutcheon and Handegord 1995)Stated that; the air leakage can cause up to 30 to $40 \%$ heat loss of the total heating requirements of properly constructed Canadian houses. There has been a growing awareness regarding energy consumption in buildings, a wide range of air-leakage 
standards for dwellings were introduced in different codes all around the world. Unfortunately, there is a challenge facing the designers to reduce the energy consumption of a building, as designers cannot rely on effective tools to help them in their decision-making process concerning air leakage. The lack of standardization restrains the development of a new air leakage predictive tool. Also, supervision and workmanship are difficult to model. Their significant impact can explain why designers and contractors find some existing models unreliable (Prignon and Van Moeseke 2017). The literature survey showed the urgent need for further work focusing on the development of a new air Leakage estimation model. This research investigates the air Leakage of Canadian houses based on measured data, the main objectives of this research are; to investigate the characteristics of air leakages of Canadian homes related to factors as construction methods, age, and size.

Awareness regarding energy consumption in buildings has been obviously growing in recent years. There was an evolution in the building code about air tightness requirements. This section presents a review of some research activities on the general behavior of air leakage in buildings and discusses different parameters affecting the air leakage performance of buildings. Before providing any analysis and discussions, the air-leakage metrics should be clearly defined. The most commonly used air leakage metrics (Sherman and Chan 2004) is stated below;

- $\quad$ CFM50 - Cubic Feet per Minute at $50 \mathrm{~Pa}$

- ELA - Equivalent leakage area at 10 Pa sq.in

- $\quad$ NLA - Normalized Leakage area = ELA/surface area sq in/ 100 sqft

- $\quad$ NLR - Normalized Leakage Rate = CFM50/surface area CFM/sqft

- $\mathrm{ACH}_{50}$ - Air change per Hour at $50 \mathrm{~Pa}=$ Volume of house/ (CFM50 X $\left.60 \mathrm{~min} / \mathrm{hr}\right)$

An investigation of 170 detached houses in Finland was done by(Jokisalo et al. 2009) An average leakage rate of $3.7 \mathrm{ACH}_{50}$ was reported and he suggested that the type of construction used has a remarkable effect on air Leakage, as the average building leakage rate of concrete, brick, and light-weight blockhouses was $2.3 \mathrm{ACH}_{50}$, while the average of the timber frame was 3.9 $\mathrm{ACH}_{50}$. In 2009, The Ministry of Municipal Affairs and Housing of Canada performed an investigation of new homes to determine the average air leakage rate of newly constructed homes and to recommend changes to the Ontario Building Code to further improve air tightness. Airtightness was tested in 100 houses, basic observations of mechanical equipment were made and details about the air barrier materials and constructions were gathered. It was concluded that the double air barrier is capable of making significant improvements in airtightness (Harris 2009).

Carrie et al. (2010) concluded that variables as structure type, area, the age of the building, number of floors and insulation type have the greatest effect on air-tightness.(T. 2000) concluded that the locations, climate conditions and zones, and the different construction techniques have a huge and significant impact on the dwellings studied in their surveys. Another investigation done in the USA (Chan et al. 2013) analyzed more than 70,000 air leakage measurements in houses across the USA to relate leakage in buildings by building size, year built, geographic region, and various construction characteristics, Based on the investigation, it was concluded that the age and floor area are the two most significant predictors of leakage area. The older and smaller houses tend to have higher normalized leakage areas than newer and larger ones

(Pan 2010) NRCan Cooperated with Canada Mortgage and Housing to investigate 163 new houses across Canada and 1811 older houses, they concluded that there is an increased trend in airtightness from $13.7 \mathrm{ACH}_{50}$ in houses built before 1921 to $3.1 \mathrm{ACH}_{50}$ in the new houses which were built in 1991 till 2009, Another study obtained from 3,759 houses in green communities, 
They concluded that the airtightness range from $4.4 \mathrm{ACH}_{50}$ in the late 90 's to $2.8 \mathrm{ACH}_{50}$ from 2005 till 2009. There are other factors which have a significant effect on air leakage as ventilators and the climatic zone which the building belongs to. These factors were discussed previously as mentioned. The literature review showed the need for studying the effect of the construction method on the air leakage performance of the buildings. Construction methods will be considered the research gap that this study will focus on. Despite the huge efforts in recent years to improve the air leakage behavior and performance of buildings, there is very few quantitative analysis regarding the relationship between air leakage and its influencing factors.

\section{METHODOLOGY}

This research intends to focus on the air-tightness of Canadian houses based on measured data. Over 226,000 air leakage measurements in dwellings across Canada were obtained the data used in this research was collected from homes aged from 1900 till 2018. In this study, the results were expressed in air changes per hour at the reference pressure $\mathrm{ACH}_{50}$. The Blower Door Test was used to measure the air leakage (in L/s) of houses under a specified pressure difference $(50 \mathrm{~Pa})$ between indoor and outdoor. "Blower Door" is a device that has an ability to pressurize or depressurize building and measure the resultant air flow and pressure through a target zone involves a blower mounted onto the frame of an exterior door. The fan pulls air out of the house lowering the internal air pressure, and because the pressure outside is higher, the air flows in through all unsealed cracks and openings. The auditors may use a smoke pencil to detect air leaks. These tests determine the air infiltration rate of a building. And this technique was used to collect the measurements used in this study, this section will discuss the factors taken into consideration during the data collection process as well as, the air leakage measurement approach used in this study.

\section{Sampling}

The air-tightness field measurements results were collected from Natural Resources Canada and a few construction companies. Three provinces were involved in this study, which are Alberta, British Columbia, and Saskatchewan. Specific information was gathered from field measurements for each house as size, age, construction methods (onsite or prefabricated in modular or panels), airtightness data including the calculated normal air change rates, house configurations, insulation levels for foundations and walls, and energy analysis data as heat loss and energy ratings. This research will focus on three points only, which are; size, age and construction methods.

\section{Influencing factors}

The investigation considers the effect of different factors, the construction period of the building is one of the factors considered in this study, and the obtained data represents the range from 1900 till 2010. Also, this data will be compared with other obtained data from previous research as mentioned in the literature review. The data set obtained has a huge variation in size, as buildings volume range varies from $100 \mathrm{~m}^{3}$ till $5500 \mathrm{~m}^{3}$. The variation with respect to volume and number of readings will be discussed in details in the next sections. Two erection methods were discussed in this research, onsite and prefabricated construction methods. The prefabricated in modular or panel's construction is described as the use of factory-produced building units that are delivered to the site and assembled, while the onsite construction is described as the building 
units are produced and assembled in the field. The comparison between the two construction methods was done by taking into consideration data with the same volume range, construction period as well as the climatic zones to obtain a statistically reliable comparison.

\section{Analysis methods}

Statistical methods were used in this study to perform all the data analysis, One-way ANOVA (Bryman and Cramer 1999, Pan 2010) analysis was utilized to compare the mean of air leakage in relation to each factor separately. An ANOVA test is a statistical method to find out if the survey or experiment results are significant. Basically, this type of analysis is commonly used and suitable in case of testing groups to see if there's a significant difference between them. All the dwellings' properties were plotted with respect to $\mathrm{ACH}_{50}$. In a few cases, the data were plotted by using the Air leakage (L/s). All comparisons and results will be discussed in details in the results section.

\section{ANALYSIS AND RESULTS}

\section{Air leakage and dwelling age}

The three provinces were considered in this investigation, the data were discretized into decades to facilitate the comparison process. Figure 1 shows the common trend in the three provinces, as the air leakage rate is directly proportional to the age, and as previously discussed that finding correlates well with the logic and previous investigations, which enhances the reliability and the accuracy of the measurements taken. Generally, it is noticed that Saskatchewan has the lowest $\mathrm{ACH}_{50}$ with respect to the other provinces, while British Colombia has the highest $\mathrm{ACH}_{50}$. Figure 1 and Table 1 discusses the average $\mathrm{ACH}_{50}$ which was calculated for each province with respect to the decade built. Then a comparison between the data obtained from this study and the literature review data is shown in Table 2.
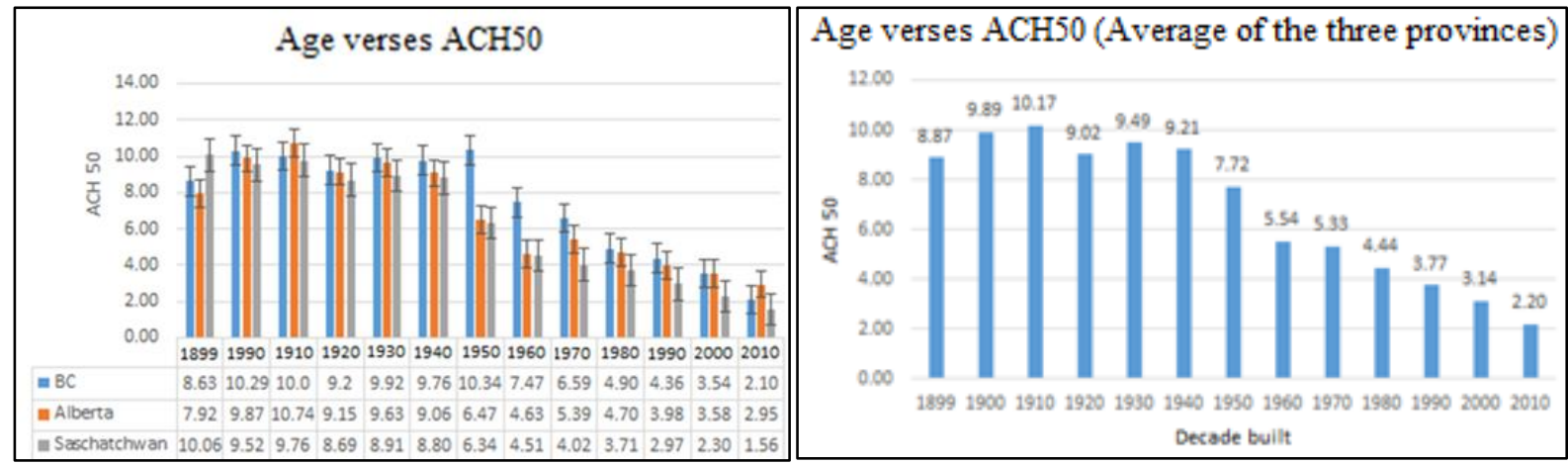

Figure 1. The relation between age and air-leakage in the three provinces

Table 1. The average $\mathrm{ACH}_{50}$ of the three provinces with respect to the decade

\begin{tabular}{|c|c|c|c|c|c|c|c|c|c|c|c|c|c|}
\hline Decade & 1899 & 1900 & 1910 & 1920 & 1930 & 1940 & 1950 & 1960 & 1970 & 1980 & 1990 & 2000 & 2010 \\
\hline $\mathrm{ACH}_{50}$ & 8.87 & 9.89 & 10.17 & 9.02 & 9.49 & 9.21 & 7.72 & 5.54 & 5.33 & 4.44 & 3.77 & 3.14 & 2.20 \\
\hline
\end{tabular}


Table 2. Comparison between this study and the previous work

\begin{tabular}{|c|c|c|c|c|c|c|c|c|c|c|}
\hline Duration & Before & $1921-$ & $1946-$ & $1961-$ & $1971-$ & $1981-$ & $1991-$ & $1995-$ & $2001-$ & $2006-$ \\
& 1921 & 1945 & 1960 & 1970 & 1980 & 1990 & 1997 & 2000 & 2005 & 2009 \\
\hline NRCan 1997 & 13.7 & 12.2 & 8.3 & 6.9 & 6.1 & 4.76 & 3.1 & & & \\
\hline GCC results & & & & & & & 4.4 & 3.7 & 3.5 & 2.8 \\
\hline This study & 9.49 & 9.35 & 7.49 & 5.44 & 4.89 & 4.10 & \multicolumn{7}{|c|}{3.45} & 2.67 \\
\hline
\end{tabular}

It was found that for Saskatchewan, British Colombia and Alberta have 7.47, 6.77 and 6.24 $\mathrm{ACH} 50$ respectively. The results within a 95\% confidence interval suggest typical distribution for all the 13-decade groups. The ratio of the between decade group mean square divided by the within groups the known $(\mathrm{F})$ value in the ANOVA analysis equals to $(\mathrm{F}=50.636, \mathrm{p}<0.01)$, $(\mathrm{F}=8.7446, \mathrm{p}<0.01)$, and $(\mathrm{F}=51.17, \mathrm{p}<0.01)$ for Alberta, British Colombia, and Saskatchewan respectively, these results imply that the differences between the means of air leakage of the dwellings built with respect to age were statistically significant, the same analysis was carried out but all values of the three provinces were merged with respect to age, the analysis showed that $\mathrm{F}=74.73, \mathrm{p}<0.01$ which emphasize that age is an important factor with respect to the air leakage from both the individual analyses and the merged analysis. It is clear that the mean of air leakage decreases when age decrease so there is a directly proportional relation between age and air leakage, such relation may be more complicated by effects from other factors, which will be investigated in this study.

\section{Air leakage and dwelling size}

The volume range $300 \mathrm{~mm}^{3}$ to $1300 \mathrm{~mm}^{3}$ has the maximum number of measurements for the three provinces, so, a preliminary analysis considered the average air leakage value with respect to this volume range, the tendency of air leakage is inversely proportional with respect with the volume, and a declining trend appears. And this trend is common in the three provinces considered. The Analysis was done for each province individually and the comparison was regarding the volume. The averages of readings indicate that the volume has an inversely proportional relation with the $\mathrm{ACH}_{50}$. From the previous analysis, there is an inversely proportional relation between size and air leakage as shown in Figure 2.

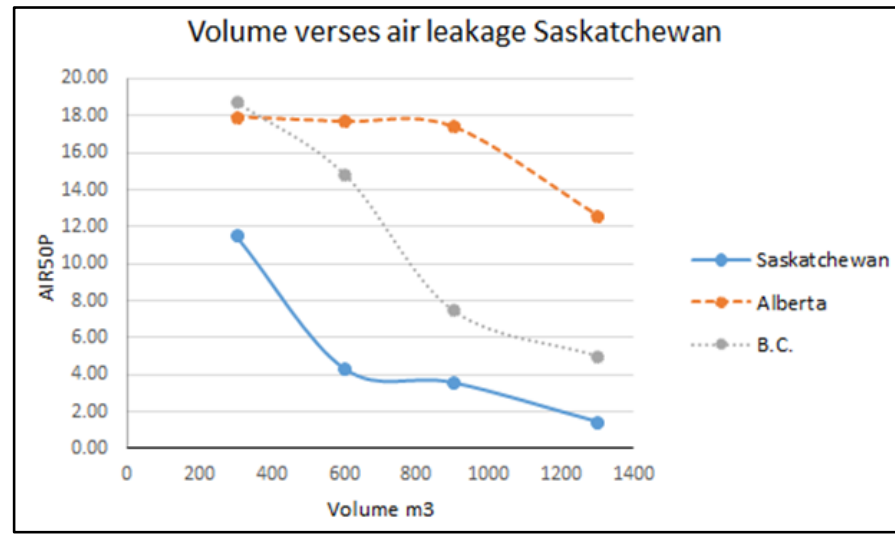

Figure 2. The relation between volume and $\mathrm{ACH}_{5}$ 


\section{Air leakage and construction method}

Two construction methods were taken into consideration, onsite and prefabricated. Investigations showed that for buildings which are mainly built onsite; have a higher tendency for air leakage than the prefabricated. The readings were categorized with respect to volume, age, dwelling type (Single attached) and climatic zone. The same number of samples of 500 measurements were considered for both construction methods in this comparison. Considering all the buildings conditions are similar while the only variable is the construction method to obtain a statistically reliable comparison. By considering the data from 2005 to 2017, it is clear that the onsite construction method has more leaky performance than the prefabricated as shown in Figure 3. It is important to mention that the workmanship and supervision's experience has a great influencing on the leakage performance in buildings, as shown in Figure 4, having a data from two different construction companies (the sample considered have the same number of measurements, The dwellings considered have the same climatic region and size), It is clear that there are differences in performance although all dwellings are having the same conditions.

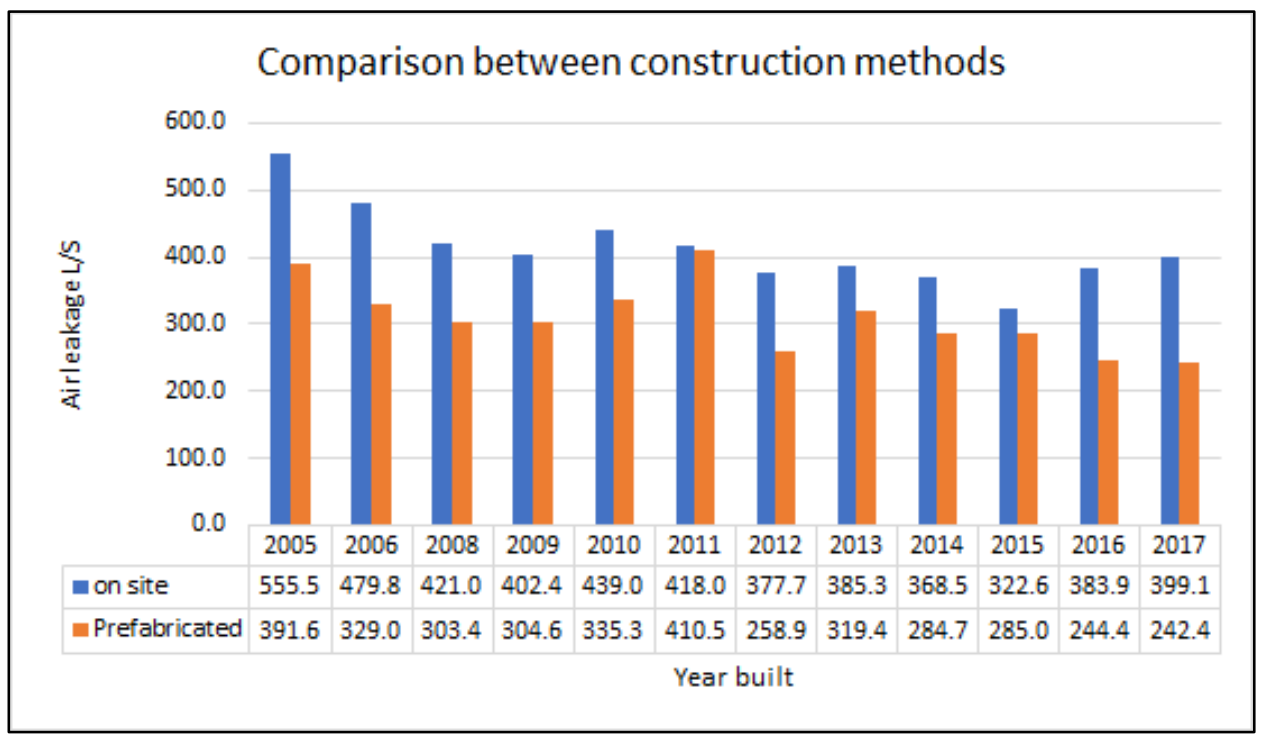

Figure 3. Comparison between the Prefabricated and onsite construction methods

Another analysis was discussed by using a wider range from 2003 till 2018 also shows the comparison between both methods as shown in Figure 4-b. The dwellings studied were constructed using two types of construction methods: onsite and Prefabricated, The mean of air leakage readings of the dwellings built using on site was higher than those built using the other construction method. The results with a $95 \%$ confidence interval suggest typical distribution for the two groups. The $(\mathrm{F}=53.867, \mathrm{p}<0.01)$ indicates that the differences between the means of air leakage of the dwellings built using the two different construction methods were significant, These results conclude that the prefabricated method has the less air leakage values with respect to onsite. 


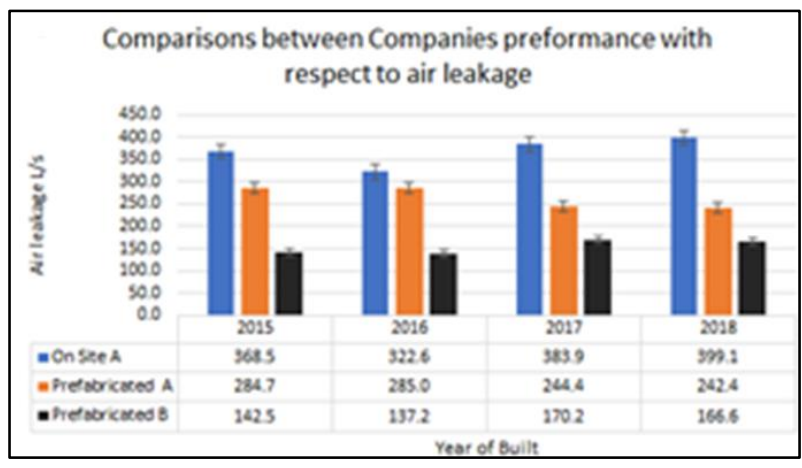

(a)

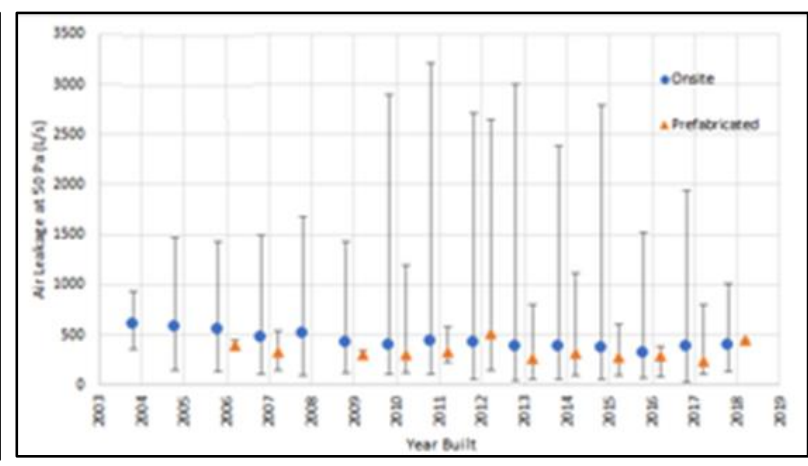

(b)

Figure 4. (a) Comparison between the prefabricated and onsite construction methods using data from two different companies, (b) comparison between both construction methods by using a wider range of data

\section{DISCUSSION}

Factors were discussed and considered in this analysis which has a direct effect on air leakage after analysis, it was concluded that each one of this parameters has a direct and high effect on the leakage performance of the building.

Age effect: It was concluded from the previous analysis that the Air leakage is directly proportional to the building age, This conclusion correlates very well with logical justifications, As when age increases cracks increases as well, and that due to time-dependent loads as creep and settlement or differential settlement that occurs in unsymmetrical buildings, So It is expected to experience more cracks with respect to time, and more cracks means more air leakage, and that was proofed by the collected data. So, now since the data correlates well with a logical explanation, the reliability of this data increased.

Size effect: The tendency of air leakage is inversely proportional with respect to the volume, the declining trend appears. And this trend is common in the three provinces considered. So the relation between the volume and the air leakage is inversely proportional, So it was concluded that as the volume increase the air leakage decrease, and also that conclusion correlate very well with(Chan et al. 2013) he concluded that older and smaller houses tend to have higher normalized leakage areas than newer and larger ones

Construction method: The construction method is a fundamental parameter which affects the air leakage behavior to a great extent, It mainly depends on the human factor as long as it reduced, we should expect error to be decreased so, air leakage also will be decreased, it was expected that onsite buildings will have the highest leakage rate, Investigations showed that the maximum leakage tendency is for the onsite buildings, as the prefabricated buildings is controlled more. As prefabricated techniques provide high levels of quality control especially at the intersections and the corners of the buildings, where higher air leakage rate is expected.

\section{CONCLUSIONS}

The investigations showed that the Air leakage is directly proportional to the building age, and inversely proportional to the size, while the prefabricated construction method has lesser leakage rate than the onsite. But it depends on the construction company's performance and experiences. It was concluded that the method of construction is a fundamental parameter which affects the air leakage behavior to a great extent, Investigations indicated that the average air leakage rate of 
onsite buildings is $412.7 \mathrm{~L} / \mathrm{S}$ while in the prefabricated method is $309.1 \mathrm{~L} / \mathrm{S}$ in period from 2005 till 2018 (having the same conditions), which is almost 35\% decrease, the human factor plays an important role in the Air leakage performance in buildings, as long as it is reduced, the air leakage also will be decreased. As the investigation showed that for the same buildings subjected to the same conditions and using the same construction method (Prefabricated), the only variable considered is the construction company, it was noticed that the air leakage value differ from $284.7 \mathrm{~L} / \mathrm{S}$ to $142.5 \mathrm{~L} / \mathrm{S}$ which is a $50 \%$ decrease in the value and that occurred only due to the differences between the companies' experiences and supervision. Investigations showed that the maximum leakage tendency is for the onsite buildings, as the prefabricated buildings are controlled more.

\section{REFERENCES}

Bryman, A., and Cramer, D. (1999). Quantitative Data Analysis with SPSS Release 8 for Windows: A guide for Social Scientists. Analysis.

Carrié, F. R., Montoya, M. I., Guyot, G., Planas, E., and Pastor, E. (2010). "Air leakage in Catalan dwellings: Developing an airtightness model and leakage airflow predictions." Building and Environment, 45(6), 1458-1469.

Chan, W. R., Joh, J., and Sherman, M. H. (2013). "Analysis of air leakage measurements of US houses." Energy and Buildings, Elsevier B.V., 66, 616-625.

Gillott, M. C., Loveday, D. L., White, J., Wood, C. J., Chmutina, K., and Vadodaria, K. (2016). "Improving the airtightness in an existing UK dwelling: The challenges, the measures and their effectiveness." Building and Environment, 95, 227-239.

Harris, J. (2009). "Air leakage in Ontario housing." DSG Home Inspections Inc./Aubrey LeBlanc Consulting.

Hutcheon, N., and Handegord, G. O. (1995). Building science for a cold climate. IRC, Canada.

Jokisalo, J., Kurnitski, J., Korpi, M., Kalamees, T., and Vinha, J. (2009). "Building leakage, infiltration, and energy performance analyses for Finnish detached houses." Building and Environment, 44(2), 377-387.

Pan, W. (2010). "Relationships between air-tightness and its influencing factors of post-2006 new-build dwellings in the UK." Building and Environment, Elsevier Ltd, 45(11), 23872399.

Prignon, M., and Van Moeseke, G. (2017). "Factors influencing airtightness and airtightness predictive models: A literature review." Energy and Buildings, Elsevier B.V., 146, 87-97.

Sherman, M. H., and Chan, R. (2004). "Building Airtightness: Research and Practice." (February).

T., S. (2000). Airtightness in UK dwellings. UK. 